\title{
EDUKIA, FORMA ETA AHANZTURA
}

\author{
Jon Mantzisidor Uria \\ Euskal Herriko Unibertsitatea (UPV/EHU). Irudigintza Saila
}

\section{Laburpena}

Testuak ohar laburretan biltzen ditu kultur adierazpide ezberdin batzuk denboraren iragaitean jasan ditzaketen aldaketak. Ohar hauek argazki eta irudiekin batera doaz, elkarren osagarri. Aukeraturiko asko hitz larriz idatziriko Arte plastikoetatik kanpo gelditzen diren adierazpenak dira, kalean gertatzen direnak edo lan munduari eta erritoei loturikoak. Hauek, gainera ez dute instituzioen kontserbazio babesik izan ohi, eta batzuk iragankor izateko sortuak izan dira. Zenbait oharrek forma eta edukiaren arteko harremanaz dihardute, zalantzan jarriz zein izan daitekeen lanaren muina. Bestetan, idazketa eta kodeak dira gai nagusia. Eta guzti honekin batera arte lan originalaren ideia aztertzen da.

\author{
Gako-hitzak: FORMA; EDUKIA; KONTSERBAZIOA; KODEAK
}

\section{CONTENT, FORM AND FORGETFULNESS}

\section{Abstract}

The text summarizes in brief notes the changes that various cultural expressions may undergo over time. These notes go hand in hand with photographs and images by the author, complementing each other. Many of the selections are expressions that are left out of the Visual Arts in capital letters, those that take place on the streets, of what are related to rituals and work world. These also lack institutional conservation programmes, and some of them have been created to be ephemeral. Some notes deal with the relationship between form and content, questioning what may be the core of the work. At other times, writing and coding are the main theme. And with all this, the idea of the authenticity and originality of the work of art is explored.

Keywords: FORM; CONTENT; CONSERVATION; CODES

\footnotetext{
Mantzisidor Uria, Jon. 2021. "Edukia, forma eta ahanztura". AusArt 9 (2): 65-74. DOI: 10.1387/ausart.23089
}

\section{AUSART}


1971. urteko berritze lanetan Cantabrian, Santa María de Lebeñako harlauza handi baten azpikaldean eguzki eta espiral irudiak topatu zituzten. X. mendeko eliza hau lehenagoko santutegi aurrekristau baten gainean eraikia izan zen. Bertako gidak zioenez zoluan zegoen harlauza handi hura nahita utzi zuten buruz behera aurreko tenpluko kideek, irudiak ezkutatuz beren sinbolo eta fedea babesteko asmoz. 1000 urte luzetan ahozpez zegoen harlauza haren gainean eman zuten meza apaiz kristauek aldarearen zolu bilakatu zenetik.

2100 urtean zigilatu asmo dute Onkalo, Finlandiako hilerri erradiaktibo erraldoia. 400 metroko sakoneran, haitzean zulaturiko tuneletan gordeko dira Finlandiako zentral nuklearretako ondakin erradiaktiboak. Gaur gaurkoz, desegin ezin daitezkeen ondakin hauek biltegiratzea beste erremediorik ez da geratzen. Asmo horrekin, datozen 100.000 urteetan Onkalon lurperaturik izateko diseinatu da proiektua, etorkizuneko gobernuek ondakinak birziklatu edo suntsitzeko teknologia izango dutenaren esperantzan. Lurrikara, uholde eta bestelakoei aurre egiteko zailtasun teknikoez gain etorkizuneko gizakiei han gordeta dagoenaren arriskuen berri nola eman erabaki behar dute; zein hizkuntza eta zein euskarritan, kontutan izanik biek ere izan dezaketen garapena. Oraingoz finlandiar gobernua Onkalo ahaztua izatea bultzako duen lege egitasmo bat adosten ari da. Ikus Michael Madsen-en Into Eternity dokumentala.

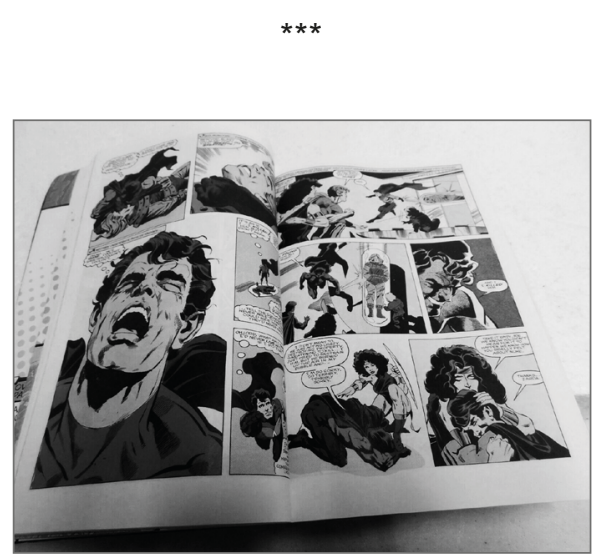

Squadron Supreme eleberri grafikoaren enkantean pujatzen ari zara$1997 k o$ bertsioa. Ale hau egoera onean dago, higadura txikiarekin eta kalte handirik EZ (ikus irudia)! Nobela grafiko honek Squadron Supreme \# 1-12 zenbakiak biltzen ditu. Komiki hau Mark Gruenwald egilearen errautsak tintan biltzen dituen lehen edizioa da! Komiki hau agortuta dago eta zaila da aurkitzen! Komiki bikaina eta ezinbestekoa edozein nobela grafiko edo Squadron Supreme zalerentzat! (Comicsvalue.com 2021) ${ }^{1}$ 
Bilboko udal langileek Amnistia hitza ezabatu eta osoa utzi dute, gainerako graffitiekin batera. (2016ko Maiatza)

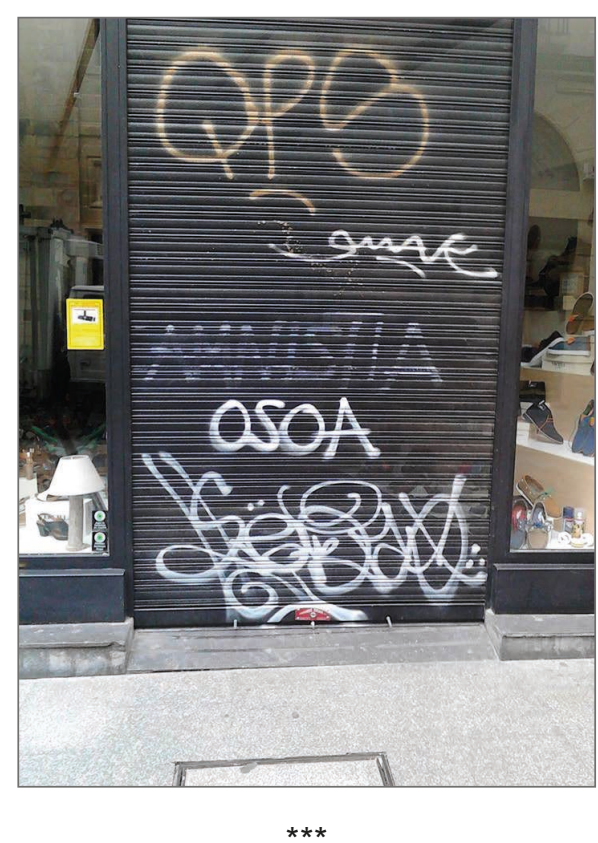

Bere maitea baztanga gaitzarekin hil zen eta berak ere, José Mauleon Gimenezek zorte bera pairatu zuen urte batzuren buruan. Hilzorian zela eskari bat egin zuen: lurpera zezatela zutik, maite mina zegoen hilobiaren aurrean, eternitate osoan hura begiratu eta babesteko. Eta hala jarri zuten hil zenean, 1869an. Europako hilobi bertikal bakanetakoa da Errioxako Alfaro hilerrian ikus daitekeen hau.
Erromatarrek I. Mendean terraza sistema ezarri aurretik, Añanako Gatzagan, Araban, zeramikazko ontziak erabili ziren gatza lortzeko 5.000 urte luzetan. Iturburu gatzatuetako urez beteta ontzi haiek sutan jartzen zituzten ura lurruntzen zen arte. Gero, gatza eskuratzeko ontziak apurtu egiten ziren. Ontzi hauetako asko, irudian ikusten den bezala, marrazki geometrikoz apainduak zeuden.

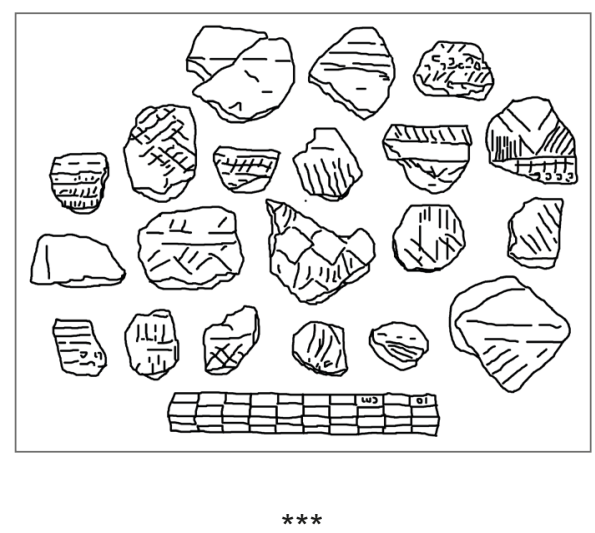

Garia jotzeko gelako hormak arrasto bertikalez josiak zeuden. 1840 ondorengo urteetan, bertan sumatzen zituen bertsoak Udarregi bertsolariak, eta alfabetatu gabea zenez teila zati batekin horman lerroak eginaz apuntatzen zituen. Gero Jose Aranburu, herriko organistari deitu eta marra haien aurrean jarrita bertsoak diktatzen zizkion eta hark paperera pasatzen. AP8 autobidea egiteko bota zuten 1972an Udarregi bizi izan zen baserria, Artikula Handi. 
Baserria bota baino lehen hormetako arrastoen molde batzuk gorde zituen Usurbilgo Udalak.

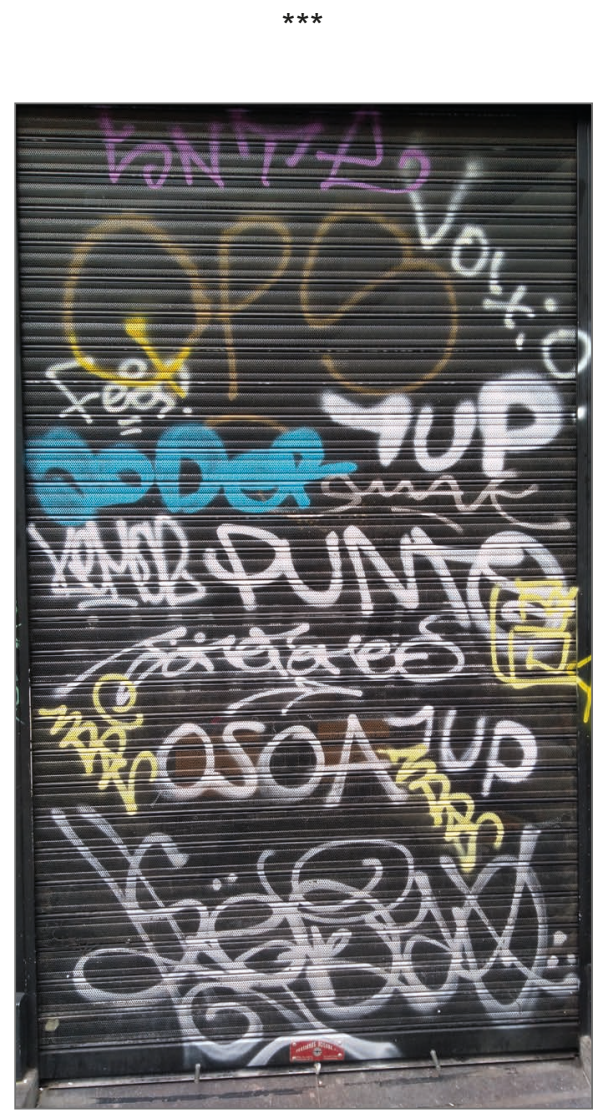

Grafitigileek osoa sinaduratzat hartu dute. Nola errespetatzen duten bere espazioa, zanpatu gabe, eta nola babesten duten hura inguratuz. (2018ko otsaila)

Irauteko asmo askorik gabe norbaitek harri txintxarrez idatzia. Bart gaueko haizete eta ekaitzak irakurgaitz bihurtu dute. Hitzak berriz ere harri txintxar izateko bidean. (Ibiza, 2018ko Apirila).

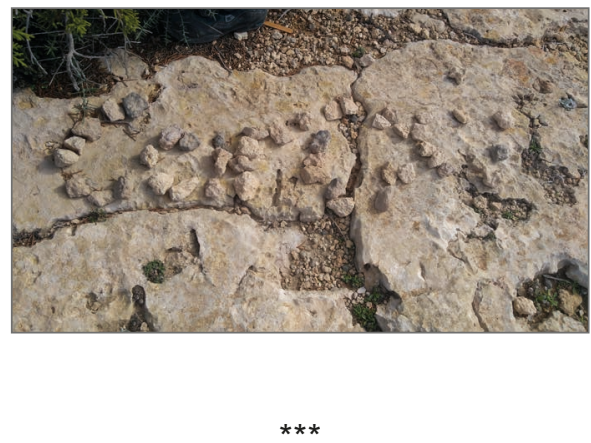

Iturburu - 6ko etxea 2006ean eraitsi zuten. XV. Mendeko eraikin hau askoren ustez Bilboko zaharrena zen. Bere elementu esanguratsuena, sarrerako arku gotikoa, auzoko biribilgune batean jarri zuten, etzanda, ia horizontalean. Harriak eta forma orokorra berberak dira baina lurrarekiko elkartzut izan ordez $30^{\circ}$ eskaseko anguluan egoteak artefaktuaren arku izaera bera zalantzan jartzen du; haren pisu eta indar harremanak, egitura eusten zuen logika guztia. 


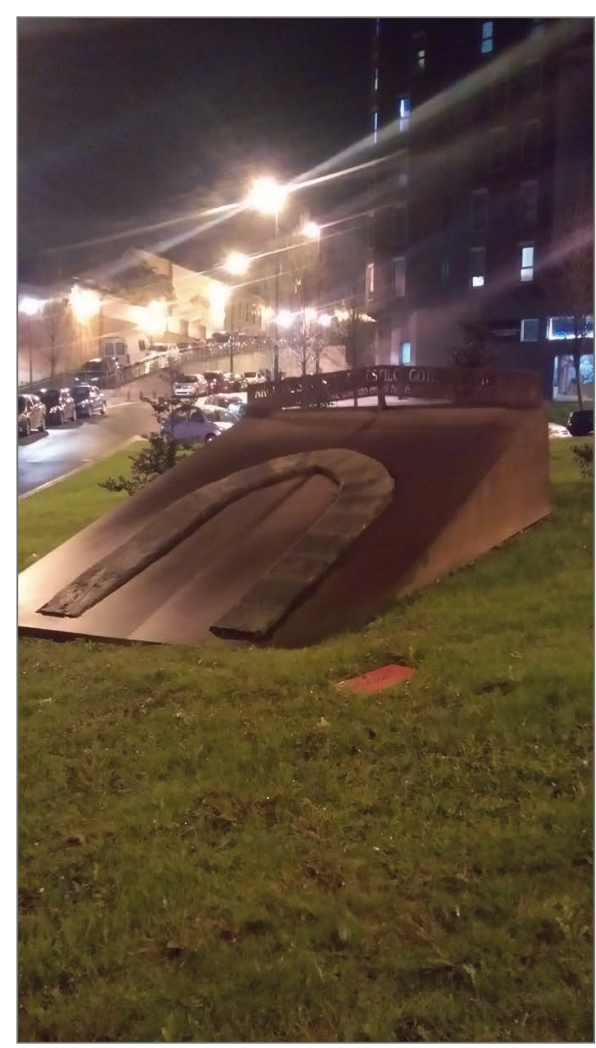

$* * *$

Ohiko irudia: Argo ontziarena (argitsua eta zuria); argonautak, pixkanaka, haren pieza guztiak ordezkatzen joan ziren, azkenean, erabat berria zen ontzi bat izan zutelarik, izena edo forma aldatu behar izan gabe. Argo ontzi hori oso erabilgarria da: alegoriari objektu nagusiki estruktural bat ematen dio, ez jeinuak, inspirazioak, determinazioak, bilakaerak sortua, baizik eta bi ekintza xumek sortua (sorkuntzaren mistika bakar batean ere atzeman ezin daitezkee- nak): ordezkapena (pieza batek beste bat lekualdatzen du, paradigma batean bezala eta izendapena (izena ez dago ezertarako piezen egonkortasunari lotua). Izen beraren baitan konbinazioak egitearen poderioz, ez da jatorrizkoaz ezer geratzen: Argo bere izena beste kausarik ez duen objektu bat da, edo bere forma ez beste identitaterik. (Barthes [1975] 2004, 64)

Jorge Oteiza, Tomas Esnaola eta Imanol Larzabalek elkarrekin bazkaldu omen zuten azken honen urtebetetzea zela eta. Bukaeran, Oteizak Imanolen irudia marraztu zuen paperezko eskuzapi batean. Hau hiretzat! esan eta han geratu omen zen paper zatia mahai gainean. Gero Imanolek Tomasi irudia garbira pasatzeko eskatu zion. Hark, pintore izanik, horman ipintzeko moduan, txukun kopiatu omen zuen.

Lekeitiotik Markinarako errepidean bide bazterreko oroigarri xume horietako bat; plastikozko loreak zutoin bati lotuak. Loreekin batera, gorago eta txukun eutsita, bizikleta baten gurpila. (2021eko Iraila)

Pinudi komertzial guztiak «antzekoak» direla azaldu du Ibarrolaren 
semeak, eta horrek Omako basoaren lekualdatzea erraztuko duela. Hala ere, onartu du bi basoak morfologikoki ezberdinak izanik, ezinbestekoa izango dela egokitzapena. Errespetuz jokatzea izango da gakoa, kasu horietan. «Saiatuko naiz ahalik eta gutxien berridazten, eta idatziko dudana Agustin Ibarrolak basoan idatzi zuen bezala idatziko dut». (Astiz 2021, 32)
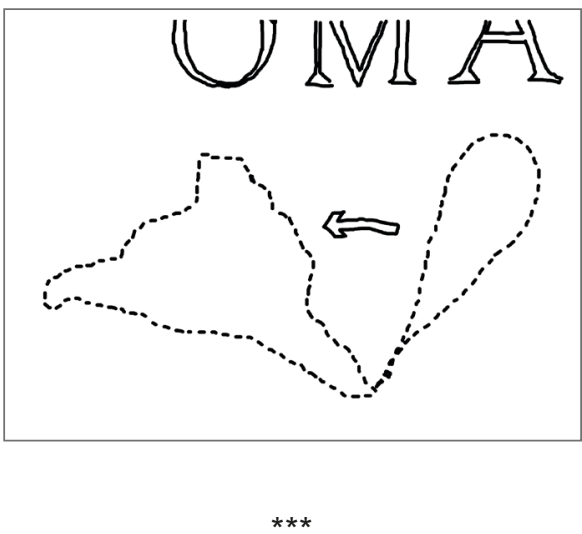

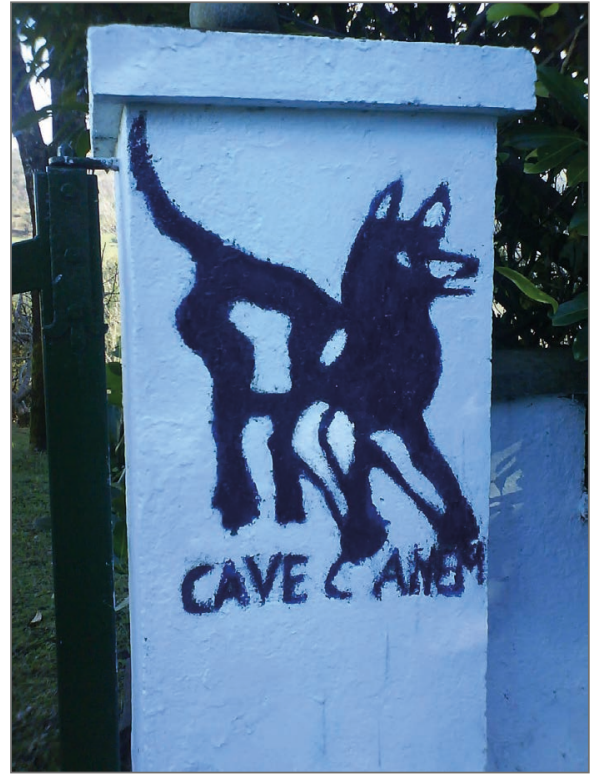

Saint-Geours Monnet familiaren txaletean irudi hau dago, gutxienez azken 40 urteotan. Aldiro, bi urtean behin edo, gainetik margotzen dute, zuria eta urdina, geruza berria zaharraren gainean.

(2015eko Martxoa).

-Antxume larrutan ere, gezurra badirudi ere, antxumea kanpolibrean ibilitakoa edo granja batean hazitakoa den kristoren aldea dago.

-Soinuan ere bai?

-Soinuan bakarrik ez, eskuan hartutakoan jada antzeman egiten diozu. Animalia estresatuta hilda badago, hura ez dago gizonik danbor partxe batean jarriko duenik.

-Zer esaten didazu? 
- Jata buelta ematen du.

(Agirre 2014, Ibon Gaztañazpik elkarrizketatua)

\section{ONDORIOAK}

Ohar bilduma moduan osaturiko testu honek bi asmori erantzun nahi lieke: batetik, eguneroko bizitzari loturiko kultur adierazpideetan ikertzea nola ematen den kontserbazioaren arazoa, eta bestetik, ikustea ea posible den ikerketa bera eguneroko bizitza horretan txertaturik egitea, alegia, kultur adierazpideak ikerlariarengana datozen moduan hartuaz esperientzien magma zabal horretan.

Hori dela eta, hiriko eguneroko ibilaldietan topaturiko graffiti edo seinaleak bildu dira eta baita oporretan aurkiturikoak ere; ikerlariaren lanak aisialdiarekin bat egiten duen lekuan. Iturri testualak izan dituztenak ere eguneroko prentsa bazterretan han hemen jasotako txatalak dira.

Zein da txatal ezberdin hauek amankomunean dutena? Ikerketa era instintiboan egin den arren, batzuetan mugikorrarekin ateratako argazki soil bidez, badaude planteatzen dituzten zenbait puntu errekurrente:

1. Artelan originalaren ideia. Cave Canem zakurraren irudian adibidez, jatorrizkoa 79 urtean
Vesubio sumendiak suntsituriko Ponpeia hirian aurkituriko mosaiko bat den arren, argazkikoa Gipuzkoan, Zumaiako Txalet baten sarreran topa dezakegu. Irudi hori etengabe margotu da 40 bat urtez, bere erreferentea hondatzen ari zen azpiko geruza bera izanik. Kanpokaldeko edozein horma berritzen den logikarekin margotu izan da irudia ere, beti berbera eta beti ezberdina, urteotako desplazamendu txiki eta bibrazioarekin.

Harrigarriagoa egiten da, Joseba Sarrionandiak Gauzak direna balira liburuan jasotako Oteizaren marrazkiaren anekdota, zeinetan Imanol Larzabal kantariak, zalantzagabeko sentsibilitatea eta artearekiko harreman zuzena zuenak nahiago izan zuen Oteizaren marrazki originalaren ordez beste pintore batek egindako kopia "txukun" bat.

Antzeko zerbait topatzen dugu Omako basoari buruzko egunkari berrian ere; Omako basoa beste pinudi batean margotuko da, eta lan honen ardura ere Ibarrolarengandik bere semearengana pasatuko da.

2. Babestu beharrekoaren funtsa zein den benetan. Kontserbatu hitza erabili ohi bada artefak- 
tuak mantentzeaz ari garenean, eta preserbatu hitza, babestu nahi dena edukiak direnean, zer babesten du adibidez Usurbilgo udalak Udarregiren arrastoen moldeak gordeaz; ez ziren jatorrizko arrastoak ere bere bertsoak eusten zituzten moldeak haiek ere? Proto-idazkera baten erregistroa dela esango da, arrazoiz seguruenik. Koderik ezean hala ere, moldearen hutsunea besterik ez zaigu geratzen. Datu hauek jaso diren Antonio Zavalaren liburu berean dator hutsune horren beste adibide muturrekoago bat. Norbaitek buruz gordetako bertso sorta bat, gero 1933an Zeruko Argia aldizkarian argitaratua eta handik Zavalak hartua bere libururako. Bertsosailak ordea hutsune bat du, memorian gorde ez zen ale bat, eta hala agertzen da, bere egitura hutsezko hezurduran.

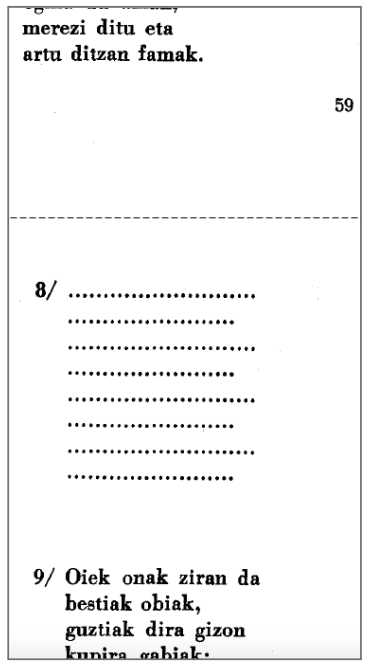

Santa María de Lebeñako harlauzaren kasuan ere, gidaren esanen arabera leku hartan ematen zen kultu aurrekristaua babestu asmoz etzan bazuten harritzarra ahozpez, zer da gaur egun mantendu dena? 1000 urte beranduago, espiral eta eguzki haiek gurtuko dituen fededunik ez dago jada egitura huts haien aurrean, gure moduko turistak soilik.

Onkaloko hondakin nuklear biltegian etorkizunera begira utzi nahi dituzten mezuek zein hizkuntza eta zein euskarri izango dituzten erabakitzeko zailtasunek ere antzeko arazoarekin egiten dute topo; kodearenarekin. Zein kode erabili, nola mantendu eta transmititu urruneko belaunaldiei.

Kodeez gain, mantendu beharrekoak elementu formal hutsak direnean ere ikusten dugu arazoak sor daitezkeela. Bilboko etxe zaharrena eraitsi zenean haren arku gotikoa gorde zen, XV. Mendekoa. Harriak jatorrizkoak izanik ere, eta forma berbera, errepide erdiko biribilgune batean etzanda jarririk, jarraitzen ote du objektu horrek arku izaten, arku gotikoaren definizioaren arabera, ez badu egitura bat eusten ezta hutsune bat sortzen? 
3. Hirugarren multzo batean iragankortasuna eta iraunkortasunari buruzko oharrak daude.

Graffitiak eta kaleko arte adierazpide asko iragankor izango direla jakinik sortuak izan dira. Oharretan ikusten den moduan etengabeko eraldaketa jasaten dute jende ezberdinaren eskuhartzeen ondorioz.

Azpimarratzekoa da Ibizan eginiko oporraldian topaturiko harriz idatzitako zerbaiten hondarra ere, haize eta euriteek desegina, erdizka ezabatua. Testua berriz ere naturako elementu izateko bidean harrapaturiko unea. Kasu honetan naturak suntsitzen badu gizakiak eginikoa, Ponpeiako sumendiaren kelarrak bere azpian harturiko artelanen kasuan babestu egin zituen mende luzetan jatorrizko Cave Canen mosaikoaren moduko lan asko.

Batzuetan, objektu baten iraunpena, danbor baten kasuan adibidez, ez da ondoren babestuz berma daitekeen zerbait, baizik eta aurrez babestu beharrekoa, objektu bihurtu aurretik hain zuzen. Azken oharrrerako transkribituriko audioko luthierrak dioenez, animaliak hiltzerakoan pairaturiko estresak danborraren soinuan eragina izango du. Estres horrek larrua ezgai bihurtzen du danbor partxe izateko. Bizitakoaren oroimenak iraungo du materialean.

Kontaezinak dira gizakiak heriotzaz gaindi iraun nahian egindako ahaleginak. Azken finean ez dute iraun asmoz egindako adibide guztiek hori bere muinean? Izan objektu bezala iraunaz, izan sinbolikoki edo ondorengoen memorian.

Hemen bildurikoen artean gizaki biziduna bertikaltasunarekin erlazionatzen duen kasu bat dago, Errioxako Alfaroko hilobiarena. Hil aurrean egindako eskariz, zutik hilobiratzean betirako atsedena ohiko esaldia ere ukatzen du hezurdura grabitatearen aurka eusten duen egitura bertikal horrek.

Iraunkortasuna betierekotasuneraino iristen da oharren batean. Zabor nuklearraren arazoa lantzen duen Into eternity dokumentalak argi azaltzen digun moduan, bizitza da egoera horretan babestu nahi dena; horretarako hondakin erradiaktiboak betiererako kontserbatzera kondenatuak daude gobernuak, oraingoz bestelako birziklapen edo suntsiketarik egiteko gai ez garenez. 100.000 urtetan irauteko eginiko tunel egitura faraonikoa. Hor daude betirako kontserbatuak berez, 
ahal izango balitz, deseginak hobe leudekeen hodakinak. Eta arriskua saiesteko, hor dagoenaren ezagutza eta oroimena bera ere ezabatzea da asmoa; belaunaldiz belaunaldi, piska- naka, informazio hori ahaztea eta inork ez gogoratzea haitzean zulaturiko tuneletan zigilaturik zer dagoen; han zerbait zegoenik ere ez jakitea.

\section{Errreferentzia bibliografikoak}

Agirre Arostegi, José Manuel. 2014. "Jose Manuel Agirre, musika tresnak egiten dituen tolosarra”. Elkarrizketatzailea, Ibon Gaztañazpi. ETBko 'Herri People' saioa, azaroak 23. Youtube bideoa, 8:31, 2014ko abenduak 4. https://www.youtube.com/watch?v=qLqFGhA4_Dc

Astiz Martinez, Iñigo. 2021. "Zaharraren mugakide da berria”. Berria, irailak 24. https://www. berria.eus/paperekoa/1879/032/001/2021-09-25/zaharraren-mugakide-da-berria.htm

Barthes, Roland. (1975) 2004. Roland Barthes por Roland Barthes. Itzulpena, Julieta Sucre. Barcelona: Kairós

Hofman, Vanina. 2019. Prácticas divergentes de preservación del arte de los medios: Recordar y olvidar en la cultura digital. Barcelona: Universitat Oberta de Catalunya

Kingsbury, Noel. (2015) 2018. Historia secreta de los árboles. Itzulpena, Margarita Gutiérrez. Barcelona: Blume

Madsen, Michael. (2010) 2019. Into eternity. Youtube bideoa, 1:18:49, irailak 27, https://www. youtube.com/watch?v=ayLxB9fV2y4

Sarrionandia Uribelarrea, Joseba. 2020. Gauzak direna balira (Habanako gaukaria). Arre, Nafarroa: Pamiela

Udarregi [Juan Jose Alkain Iruretagoiena]. 1966. Udarregi bertsolaria. Biltzailea, Antonio Zavala. Tolosa: Auspoa

Urkizu Adrian, Urtzi. 2021. “Eternitatea zutunik”. Berria, uztailak 25. https://www.berria.eus/ paperekoa/1957/048/001/2021-07-25/eternitatea-zutunik.htm

\section{Oharrak}

1 "Squadron Supreme TPB Marvel 1997 SC first print edition Mark Gruenwald Ashes Ink". https://www.comicsvalue.com/Squadron-Supreme-TPB-Marvel-1997-SC-First-Print-Edition-Mark-Gruenwald-Ashes-Ink/171897709731.html 